Gentlemen, when your paticnt can afford it, is /about his head, and a few drops of blood escaped no inconsiderabie adjuvant to all our remedial several times from his nostrils. 'This subsided; his agents.

appetite became good, and he ate plentiful meals of meat, and drank porter, \&c. He gradually recovered his strength. The urine improved under the use of

SUCCESSFUL CASE OF TRANSFUSION OF BLOOD.

TO THE EDITORS OF THE PROVINCIAL MEDICAL JOURNAL.

Gentlemen,-A desire having been expressed by a correspondent, in the last Number of your Journal, that the particulars of a case mentioned at the Medical Association for Bath and Bristol, in which transfusion of blood was practised, should be published, I think it right to comply with that wish, and shall do it in as few words as possible.

The patient alluded to is a mercantile man, who had been in the habit of travelling in pursuit of his commercial business. He had been a strong, active man, and had lived as persons of his vocation generally do, but more temperately than many. When I saw him first, on the 1lth of January, 1834, he had been upwards of two years an invalid, and had been under the care of Mr. Henry Clark, one of the surgeons of the Bristol Infirmary - a medical practitioner of great skill in this city. For some short time he had also been visited by Dr. Riley, and by these gentlemen I was called to see the patient. His early complaints had been of dyspeptic symptoms. These were followed by emaciation and loss of strength. His actual state was that of extreme inanition,; his pulse was feeble, jerking, very compressible, the calibre of the artery apparently not filled; he had palpitation of the heart, increased by the slightest exertion, while any effort brought on an approach to syncope. No disease was discoverable by the sounds of the heart or respiratory organs, though some suspicion was entertained of slight dilatation.

The state of the urine alone threw some light on the nature of the disease. It had long deposited a very copious sediment, of a whitish color, slightly tinged with purple, which was redissolved by dilution, with the addition of an alkali. It appeared to consist of lithates, with some chyle; and it was thought probable by the medical gentleman who had previously attended the patient, and by myself at our first meeting, that an exhausted and exsanguineous state, brought on by a long continued draining of the system, constituted the principal disease, or at least that which first required attention. Under these circumstances, it was determined to try a restorative and repletive plan. A nourishing diet was ordered, with malt liquor and some other stimulants. His stomach would receive but little, and at length rejected food. His exhaustion increased to that degree that immediate fatal syncope was threatened. We determined, the patient being obviously in extremis, to try the effect of transfusion, and as patients under cholera had borne the injection of large quantities of fluid, there seemed to be no danger in injecting a considerable quantity of blood. Sixteen ounces were taken from the veins of a hale young man, a servant of the patient, and were injected most skilfully by $\mathrm{Mr}$. Clark. The patient was immediately revived and roused. On the following day he appeared much stronger, but complained of some sense of fulness alkalies with lime-water, and these were nearly all the remedies used except a few bottles of an effervescing solution of citrate of iron. After two or three months he left his chamber, and then his house, and I understand he is now travelling on commercial business.

I think it may be inferred from the facts of this case that many lives may be saved by injecting good blood into the veins of exhausted patients, and, perhaps, this measure may become hereafter as important a remedial measure as the detraction of blood has been since the time of Hippocrates.

I am, Gentlemen,

Your obedient servant,

J. C. Prichard, M.D., F.R.S., M.R.I.A.,

Corresponding Member of the Institute of France, and of the Royal Academy of Medicine, sc.

Bristol, July 18, 1843.

\section{A CASE OF GOUT,}

IN WHICH

\section{THE WATER-CURE WAS FOLLOWED BY DISEASED} HEART, DROPSY, AND DEATH.

By Charles Hastings, M.D., F. G. S.

There exists no doubt in my mind that one great cause of the spurious celebrity of the Silesian peasant, Priessnitz, is that he has cunningly succeeded in turning the love of the marvellous, which is known to be a principle inherent in the human breast, to his own selfish ends. Every unprejudiced account which we reccive from Graefenburgh confirms this opinion, by showing that there is little faith to be placed in the reputed cures there performed.

The cures said to be effected by the hydropathists are as wonderful as those of Prince Hohenlohe, and somewhat of the same faith which distinguished his disciples animates the hydro-maniacs.

Dr. Pfeufer, directing physician of the Universal Hospital at Bamberg, thus describes the scene of operation of this princely priest, and the rush of the infatuated sufferers from disease to his presence:"Let us (he says) then imagine thousands and thousands of human beings under such circumstances, to each of whom every day brings new sufferings, new despondence, and who have but one wish remainingrelease by death from their nameless pangs. Electrified by the news that at Bamberg and Würzburg there is help and salvation for them through the grace of God, a new life glows within them, and already they feel the term of their misery. With the same longing as that of the leper for the pool of Bethesda, they hurry to the place where all grief vanishes, and where the stream of health and deliverance flows. In ever increasing expectation, and with breasts full of hope, wholly occupied in anticipating the enjoy. ment of re-established health, dead to every other thought, they approach the scene of healing grace. At every step are announced to them the great wonders that take place there every minute. Scarcely arrived at the place of deliverance, they throw themselves at the foot of the altar, confess their sins, and, reconciled 